\title{
Food Composition and Acid-Base Balance: Alimentary Acid Load and Clinical Implications in Neonates
}

\author{
Hermann Kalhoff*,, ${ }^{*}$ Friedrich Manz ${ }^{2}$, Peter Kiwull ${ }^{3}$ and Heidrun Kiwull-Schöne ${ }^{3}$ \\ ${ }^{1}$ Pediatric Clinic, Beurhausstrasse 40, D-44137 Dortmund, Germany; ${ }^{2}$ Research Institute of Child Nutrition, 44225 \\ Dortmund, Germany; ${ }^{3}$ Department of Physiology, Faculty of Medicine, Ruhr-University, 44780 Bochum, Germany
}

\begin{abstract}
In preterm neonates, functional limits of pulmonary and/or renal regulation processes and the considerable acid load of common formulas predispose to a great risk for the development of latent metabolic acidosis, characterized by e.g. impaired mineralization and reduced growth. Furthermore, in a prospective study in very low birth weight-infants, latent metabolic acidosis was assumed to contribute to the development of nephrocalcinosis. To obtain fundamental data of acidbase regulation in preterm infants under different diets, we investigated 48 preterm infants fed their own mother`s milk (28 native human milk, 20 enriched with fortifier) and 34 patients on formula ( 23 on a standard batch, 11 on a modified batch with reduced acid load). Irrespective of the diet, we could not find notable differences between individual data of acid-base status in blood samples. In contrast, dietary acid-base intake was accurately reflected in the urine, pointing to effective individual compensation of alimentary acid-load by renal base saving mechanisms. Thus, in preterm infants, nutritional acid-base challenges can be judged earlier and more safely by urinary than by blood acid-base analysis A physiologically based and empirically adjusted calculation model allows to estimate the impact of mineral and protein content of a formula on the urinary ionogram and thus on the average renal net acid excretion in a regularly fed and growing preterm infant. The algorithm of this proposed calculation model could prove to be a useful tool in the design of new formulas with adaequate base supply for preterm infants.
\end{abstract}

Keywords: Nutrition, preterm infants, acid-base intake, renal acid-base excretion, metabolic acidosis.

Conference Paper, presented at the $2^{\text {nd }}$ International Acid-Base Symposium, Nutrition - Health - Disease in Munich, Germany, September 2006.

\section{INTRODUCTION}

In small preterm babies, renal acid excretion capacity is low compared to term newborns [1]. However, nutrition with standard formulas already may result in an actual renal acid excretion (NAE) in the range of maximum renal acid excretion. This predisposes the preterm neonate to a great risk for the development of a positive acid balance, i.e. a tendency towards development of metabolic acidosis [2]. Although this diet-induced incipient metabolic acidosis does not produce major changes in the blood $\mathrm{pH}$, it is associated with ongoing consumption of endogenous buffer reserves, clinically characterized by e.g. impaired bone mineralization and impaired growth [3]. The results of a prospective study in preterm neonates with birth weight below $1,500 \mathrm{~g}$ suggested that impaired acid-base homeostasis with a tendency towards metabolic acidosis might contribute to hypercalciuria and thus development of nephrocalcinosis in preterm infants [4].

Renal NAE in preterm infants is low on nutrition with human milk [3]. Moreover, human milk may contribute positively to a preterm infant's health and development [5], provided that the nutritional inadequacies of human milk for preterm infants are corrected, e.g. by fortifiers providing additional factors like minerals and protein $[6,7]$. On formula, renal NAE of preterm infants was significantly decreased by modification of solely the mineral content of a

\footnotetext{
*Address correspondence to this author at the Pediatric Clinic, Beurhausstrasse 40, D-44137 Dortmund, Germany;

E-mail: Hermann.Kalhoff@klinikumdo.de
}

standard formula, thus effectively preventing the development of latent metabolic acidosis [8]. We wanted to analyse the impact of food mineral composition and renal regulation on systemic acid-base regulation in preterm infants either on human milk (native or fortified) or on formula (standard formula or modified formula with reduced acid load).

\section{MATERIALS AND METHODS}

We investigated 82 preterm infants with body weight $<2.0 \mathrm{~kg}$ treated in the neonatal ward of the paediatric clinic in Dortmund from 1993 to 1994 [9]. All patients were fed according to the standard regimen of the ward (a supplement of vitamin D ( $25 \mu \mathrm{g} /$ day) was started on day 10). 48 infants were fed their own mother's milk, in 20 of these human milk was supplemented with fortifier (Nestlé FM 85, at that time $5 \mathrm{~g}$ per $100 \mathrm{ml}: 0.8 \mathrm{~g}$ protein, $3.6 \mathrm{~g}$ carbohydrates, $1.2 \mathrm{mmol}$ sodium, $0.3 \mathrm{mmol}$ potassium, $1.3 \mathrm{mmol}$ calcium, $1.1 \mathrm{mmol}$ phosphorus, $0.5 \mathrm{mmol}$ chloride, $0.1 \mathrm{mmol}$ magnesium). From 34 preterm infants on formula, 23 patients were fed a standard batch (Prematil, Milupa, Friedrichsdorf, Germany), and 11 patients a modified batch of this formula with reduced acid load [8]. Patients on formula received a calciumphophorus supplement (increasing $\mathrm{Ca}$ concentration to a total $\mathrm{Ca}$ content of $4.2-4.3 \mathrm{mEq} / \mathrm{dl}$ and $\mathrm{P}$ concentration to a total P content of $2.4-2.5 \mathrm{mEq} / \mathrm{dl}$ ). Electrolyte composition of formulas and of human milk was determined by own analysis of the ashes (Table $\mathbf{1}$ ).

In all patients, timed urine samples were collected for 8$12 \mathrm{~h}$, using a specially designed freezer $\left(-20^{\circ} \mathrm{C}\right)$ with a sensor and a printer to register the time of micturition. The elec- 
Table 1. Average data for diet composition (native low-protein human milk (MM), high-protein human milk (MMF) enriched with fortifier Nestlé FM $85(5 \mathrm{~g}$ per $100 \mathrm{ml})$, standard formula for preterm infants (Prematil $\left.{ }^{\circledR}\right)$ with higher acid load (FH), a modified batch formula with reduced acid load (FL)), for patients characteristics (age, weight, nutritional characteristics), and for 'urinary ph' (pHu) and net acid excretion (NAE) in 82 preterm infants on four different diets. 1 mmol rep-

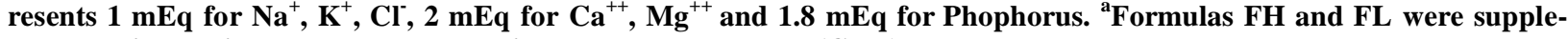
mented with calcium-L-lactate and calcium-glycero-phosphate (Ca-P)

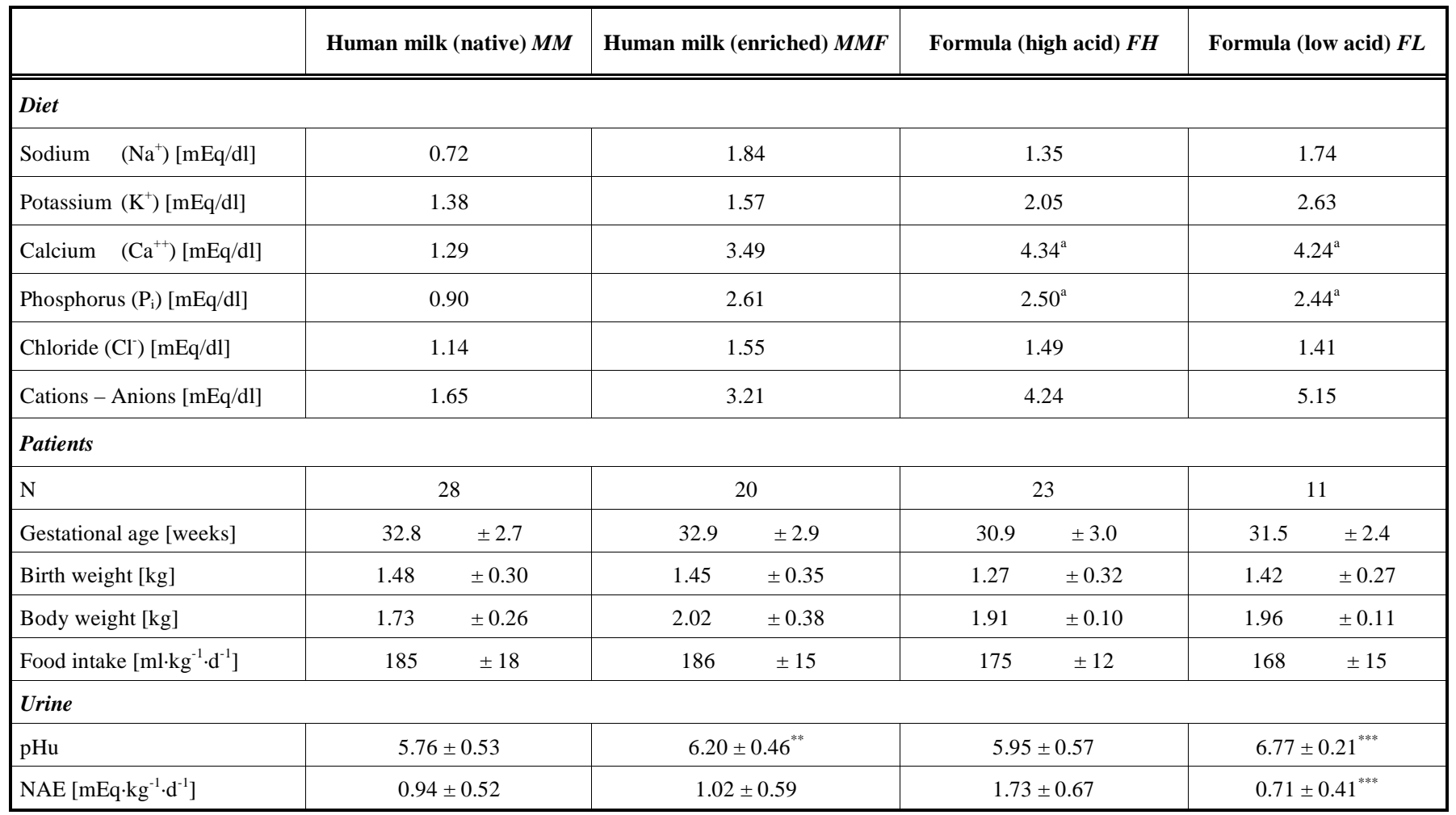

${ }^{a}$ Formulas FH and FL were supplemented with calcium-L-lactate and calcium-glycerophosphate (Ca-P).

Significant differences between groups are indicated as $* * \mathrm{p}<0.01$ and $* * * \mathrm{p}<0.001$ (independent samples, t-test).

trolyte content of the blood as well as urinary concentrations of creatinine, $\mathrm{Na}, \mathrm{K}, \mathrm{Ca}, \mathrm{Mg}$, chloride and phosphate were assayed by standard methods. Urinary concentrations of titratable acidity, ammonium, and bicarbonate were determined as described by [10], the organic acids were measured by titration [11] with a Memotitrator DL, 40 RC (MettlerToledo, Gießen, Germany), and sulfate was determined with a Dionex 10 Ion Chromatograph (DionexGmbH, Weiterstadt, Germany). For phosphate, conversion of $\mathrm{mmol}$ in $\mathrm{mEq}$ is based on measured $\mathrm{pH}$-values in capillary blood samples or urine, thus considering, respectively, the ratio of primary and secondary phosphate. Renal net acid excretion (NAE) corresponds to the sum of titratable acidity and ammonium minus bicarbonate. Daily renal base excretion (Fig. 2) was assessed as sodium plus potassium minus chloride in collected urine. The difference between "fixed cations" and "fixed anions" from the ash analysis provides a measure of different nutritional acidity and/or "potential renal acid-base load" $[12,13]$.

For inter-individual correlation analysis (Figs. 1 and 2), dietary alkali excess was calculated from diet's ash cationanion difference and individual data of daily food intake for each patient. To assess the acid-base status of the blood, base excess (BE) can be read from the Siggaard-Andersen Nomogram for any given pair of blood $\mathrm{pH}$ and $\mathrm{PCO}_{2}$ (Blutgassystem Corning 278, Ciba-Corning, Gießen).

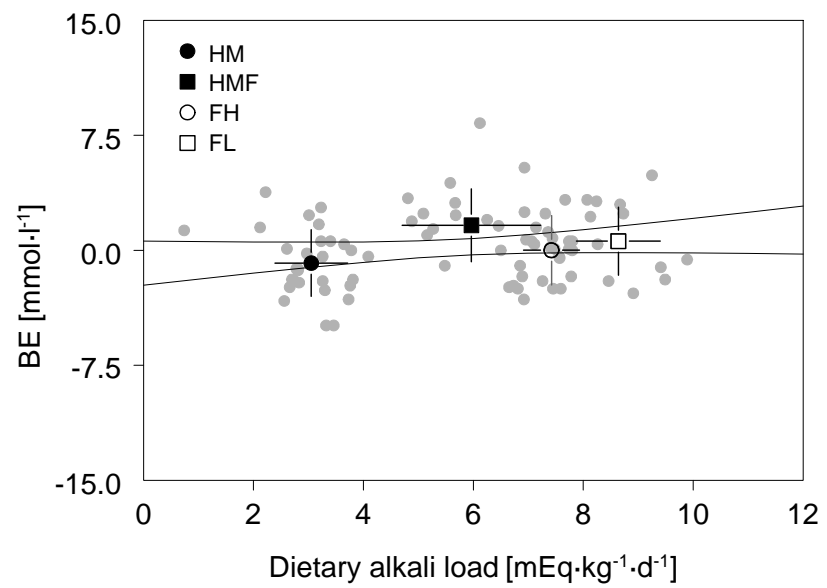

Fig. (1). Effect of dietary alkali load on arterial base excess. Ordinate: Arterial base excess (BE) determined in 82 preterm infants on different diets. Dietary alkali load was calculated from diets' ash cation-anion difference and daily milk intake. Mean values \pm SD are given for each diet. Linear regression analysis $(y=0.18 x-0.83$, $\mathrm{n}=82, \mathrm{r}=0.17 \mathrm{n} . \mathrm{s}$.) includes the $95 \%$ mean confidence interval over the whole range of dietary alkali load.

Data were analyzed by SPSS statistical software, first calculating group mean values and standard deviations (SD). 
Variables were tested for normal distribution by the one sample Kolmogorov-Smirnov test. For the groups on different types of nutrition, with native human milk (MM), with fortified human milk (MMF), with a standard preterm milk formula (FH) and with a modified low-acidogenic formula (FL), differences of mean values were tested for significance by independent samples t-tests. $\mathrm{P}$ values $\leq 0.05$ were accepted as significant. The degree of correlation between pooled variables of all groups was determined by linear regression analysis, regression lines being characterized by slopes, intercepts and $95 \%$ mean confidence intervals.

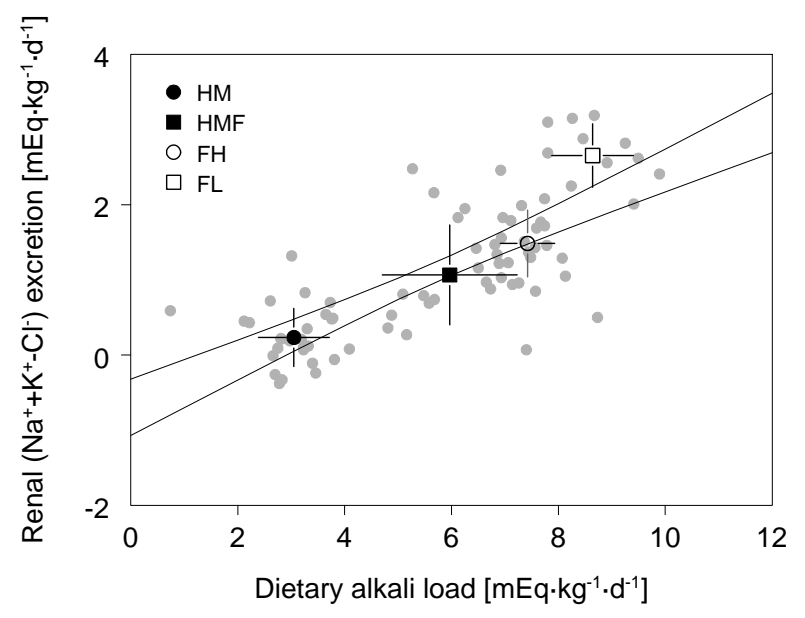

Fig. (2). Effect of dietary alkali load on renal $\left(\mathrm{Na}^{+}+\mathrm{K}^{+}-\mathrm{Cl}^{-}\right)$excretion. Ordinate: Daily renal sodium plus potassium minus chloride excretion determined in urine sampled from 80 preterm infants on different diets. Dietary alkali load was calculated from diets' ash cation-anion difference. Mean values \pm SD are given for each diet. Linear regression analysis $(\mathrm{y}=0.32 \mathrm{x}-0.70, \mathrm{n}=80, \mathrm{r}=0.77$, $\mathrm{P}<0.0001$ ) includes the $95 \%$ mean confidence interval over the whole range of dietary alkali load.

\section{RESULTS AND DISCUSSION}

\section{Diet Composition, Patient Characteristics, Urinary Acid Excretion}

Considering fixed cation-anion difference of intake, preterm formulas provided higher values than human milk, mainly due to the higher contents of potassium and calcium. The difference of cations and anions, representing one important determinant of "potential bicarbonate of a diet" [14], were increased by fortification of human milk, nearly reaching the range found in formula. There were no significant differences in gestational age and birth weight between the two groups on either human milk or on formula; food intake tended to be higher on human milk. Net acid excretion was about similar on either native or fortified human milk (about $1 \mathrm{mEq} / \mathrm{kg} / \mathrm{d})$; but high in the standard formula (1.73 $\mathrm{mEq} / \mathrm{kg} / \mathrm{d}$ ) and was lowest in the modified formula with reduced acid load. On formula, mean urine $\mathrm{pH}$-values mirrored the significant reduction of acid load achieved by modification (FL) of the standard formula (FH). In human milk, fortification had no significant impact on net acid excretion, but nevertheless resulted in a small, but significant increase of urine-pH values.

\section{Systemic Base Excess, Renal Base Excretion}

Systemic base excess was maintained nearly constant over a wide range of dietary alkali load, linear regression analysis (Fig. 1) not showing any significant correlation between capillary base excess and dietary alkali load. In contrast, renal base excretion effectively mirrored the individual variations in dietary alkali intake (Fig. 2).

\section{Acid-Base Balance}

The neonate, as the adult, must excrete acid equivalents generated from metabolism in the form of ammonia and titratable acid. When net acid excretion is unable to match the non-volatile acids produced daily, positive acid balance leads to incipient or latent metabolic acidosis, and finally may result in manifest metabolic acidosis [2,3].

Our data show that pronounced differences in dietary alkali were responded to by proportional rates of renal base excretion. On the contrary, capillary blood samples, reflecting systemic acid-base status of the blood, were without any clinical diagnostic value in the individual infant, irrespective of development of latent metabolic acidosis. Only recently, a systematic analysis of food mineral composition and acidbase balance in rabbits demonstrated that dietary base variations were more accurately reflected in the urine than by the blood acid-base status [15].

\section{Estimation of Renal Net Acid Excretion}

In adults under steady state conditions, the impact of a given diet on systemic acid-base balance can be estimated, e.g., using a physiologically based calculation model to predict renal net acid excretion by analysing intake, intestinal absorption and metabolism of several nutrients $[12,16]$. Recently our group proposed a physiologically based and empirically adjusted algorithm to estimate renal NAE from the analytical data of a formula (electrolyte and protein content) [17]. The model helps to estimate the impact of mineral composition and protein content of a formula on the urinary ionogram and thus on the average renal NAE. This algorithm could prove to be useful in the design of formulas with adaequate base supply for preterm infants.

\section{REFERENCES}

[1] Manz F, Kalhoff H, Remer T. Renal acid excretion in early infancy. Pediatr Nephrol 1997; 11: 231-243.

[2] Kalhoff H, Manz F, Diekmann L, Kunz C, Stock GJ, Weisser F Decreased growth rate of low-birth-weight infants with prolonged maximum renal acid stimulation. Acta Paediatr 1993; 82: 522-527.

[3] Kalhoff H, Manz F. Nutrition, acid-base status and growth in early childhood. Eur J Nutr 2001; 40: 221-230.

[4] Hein G, Richter D, Manz F, Weitzel D, Kalhoff H. Development of nephrocalcinosis in very low birth weight infants. Pediatr Nephrol 2004; 19: 616-620.

[5] Schanler RJ. Human milk fortification for premature infants. Am J Clin Nutr 1996; 64: 249-250.

[6] Lucas A, Fewtrell MS, Morley R, et al. Randomized outcome trial of human milk fortification and developmental outcome in preterm infants. Am J Clin Nutr 1996; 64: 142-151.

[7] Carlson SE. Feeding after discharge: growth, development and long-term effects. In: Tsang RC, Lucas A, Uauy R. Koletzko B, Zlotkin S, editors. Nutrition of the preterm infant. Scientific basis and practical guidelines, Cincinnati: Digital Educational Publishing Inc; 2005; pp. 357-382.

[8] Kalhoff H, Diekmann L, Hettrich B, Rudloff S, Stock GJ, Manz F. Modified cow's milk formula with reduced renal acid load preventing incipient late metabolic acidosis in premature infants. J Pediatr Gastroent Nutr 1997; 25: 46-50. 
[9] Kalhoff H, Manz F, Kiwull P, Kiwull-Schöne H. Food mineral composition and acid-base balance in preterm infants. Eur J Nutr 2007; 46: 188-195.

[10] Lüthy C, Moser C, Oetliker O. Dreistufige Säure-Basen-Titration im Urin. Med Lab 1977; 30: 174-181.

[11] van Slyke D, Palmer WW. Studies in acidosis. The titration of organic acids in urine. J Biol Chem 1920; 41: 567-585.

[12] Remer T, Manz F. Potential renal acid load of foods and its influence on urine pH. J Am Diet Assoc 1995; 95: 791-797.

[13] Remer T. Influence of nutrition on acid-base balance - metabolic aspects. Eur J Nutr 2001; 40: 214-220.
[14] Emmett M, Alpern RJ, Seldin DW. Metabolic acidosis. In: Seldin DW, Giebisch G, editors. The Kidney: Physiology and Pathophysiology, New York: Raven Press, Ltd; 1992; pp. 2759-2836.

[15] Kiwull-Schöne H, Kalhoff H, Manz F, Kiwull P. Food mineral composition and acid-base balance in rabbits. Eur J Nutr 2005; 44 : 499-508.

[16] Remer T, Manz F. Estimation of the renal net acid excretion by adults consuming diets containing variable amounts of protein. Am J Clin Nutr 1994; 59: 1356-61.

[17] Kalhoff H, Manz F. Estimation of dietary acid load of formulas for preterm infants. Eur Food Res Technol 2005; 220: 96-100. 